“ (C) 2017 IEEE. Personal use of this material is permitted. Permission from IEEE must be obtained for all other uses, in any current or future media, including

reprinting/republishing this material for advertising or promotional purposes, creating new collective works, for resale or redistribution to servers or lists, or reuse of any copyrighted component of this work in other works." 


\section{Wind farm grounding system analysis}

\author{
Massood Keshavarz Siahpoosh \\ University of Technology Sydney \\ Sydney, Australia \\ Massood.KeshavarzSiahpoosh@student.uts.edu.au
}

\author{
David Dorrell \\ University of Kwazulu-Natal \\ Kwazulu-Natal, South Africa
}

\author{
$\mathrm{Li} \mathrm{Li}$ \\ University of Technology Sydney \\ Sydney, Australia
}

\begin{abstract}
- this paper studies a real-case grounding system design for a wind farm and associated equipment. The design is based on the safety criteria provided by Australian and International guidelines listed in the references [1-5]. The wind farm grounding system consists of wind turbine generators, tower base padmounts, $33 \mathrm{kV}$ cable screen and a primary substation. In this paper, grounding system and ground potential rise analyses are presented and discussed.
\end{abstract}

In this study, the conventional earthing system of a wind farm has been assessed. The impacts of turbines foundation reinforcement, tower base substation, intersconnection cables and mutual coupling between neighboring turbines grounding systems have been simulated. Several methods of improvement are proposed accordingly.

Since it is more likely to have farm animals in the vicinity of a wind turbine during the phase to ground fault a new method for calculation of safe step voltage for farm animals has been proposed.

Keywords - component; ground electrode, step and touch voltage, tower base padmount

\section{INTRODUCTION}

The grounding system analysis consists of the below two main stages:

- Design stage analysis

- Commissioning and operational stage

Design stage normally starts with site investigation and soil resistivity measurement. Next step is safe step and touch voltage calculation based on contact scenarios, fault level and fault clearance time. After defining safe operational limits, the actual installation modeling and software simulation of phase to ground fault at the turbine tower base padmount and primary substation is required. The grounding system should be designed to ensure the safety of nearby people, farm animals and integrity of equipment in the event of phase to ground faults or lightning strokes in the substation and wind turbines [6].

It is a common practice to conduct 3 pin fall-of- potential test after installation of ground electrodes (during construction) to measure the grounding system resistance prior to energisation.

Normally during the commissioning stage, the performance of wind turbine and primary substation will be evaluated by current injection test to validate design characteristics. The operators of wind farms have different maintenance regimes for testing the resistance of their assets grounding system. The ground rod resistivity test period depends on soil acidity and alkalinity level and can vary between 2 to 5 years.

\section{DESIGN STAGE}

\section{A. Site Investigation and Soil Resistivity Testing}

Soil electrical resistance has an important role in phase to ground fault dissipation and fault current return path. There are several methods to estimate soil resistivity of wind farms. Industry practice is to use the combination of the following methods:

- Geological information and soil samples

- $\quad$ Four-point method (current injection method)

As described in IEEE Std 81 [1], The following methods are applied for four-point soil resistivity measurements:

- $\quad$ Equally Spaced or Wenner

- Unequally Spaced or Schlumberger-Palmer

The common method for wind turbine soil measurement is the equally spaced Wenner Arrangement. Wenner array soil resistivity testing should ideally be done for two perpendicular traverses at the proposed location of the wind turbine, with the electrode spacing up to 3 times of diagonal of the grounding system (wind turbine foundation). The pin spacing for each measurement traverse (between adjacent pins) should be at 6" to 12 " and increase thereafter in a logarithmic, fashion up to the maximum pin spacing chosen for that traverse. The spacing should generally cover $1,2,4,8,16,32,50$ and $100 \mathrm{~m}$. Normally wind turbines are located on elevated areas scattered across a large-sized site. As a result, a large number of soil resistivity measurements should be carried out at the substation area and at the wind turbine locations. In addition, elevated land has higher soil resistivity in most cases. The RESAP module of the CDEGS software was used to determine the soil structures and the simulation curve is presented in Fig. 1. The soil model used for this study is shown in Table 1.

TABLE I.

SOIL MOdEL OF WIND FARM CASE STUDY

\begin{tabular}{|l|c|c|c|}
\hline \multirow{2}{*}{$\begin{array}{c}\text { Soil } \\
\text { Layers }\end{array}$} & \multicolumn{3}{|c|}{ Soil Characteristic- Wenner Measurement } \\
\cline { 2 - 3 } & Resistivity $(\mathbf{\Omega} \boldsymbol{m})$ & Thickness $(\boldsymbol{m})$ & RMS Error \\
\hline Top & 163.00 & 11 & \multirow{2}{*}{$8.068 \%$} \\
\hline Bottom & 553.00 & Infinite & \\
\hline
\end{tabular}




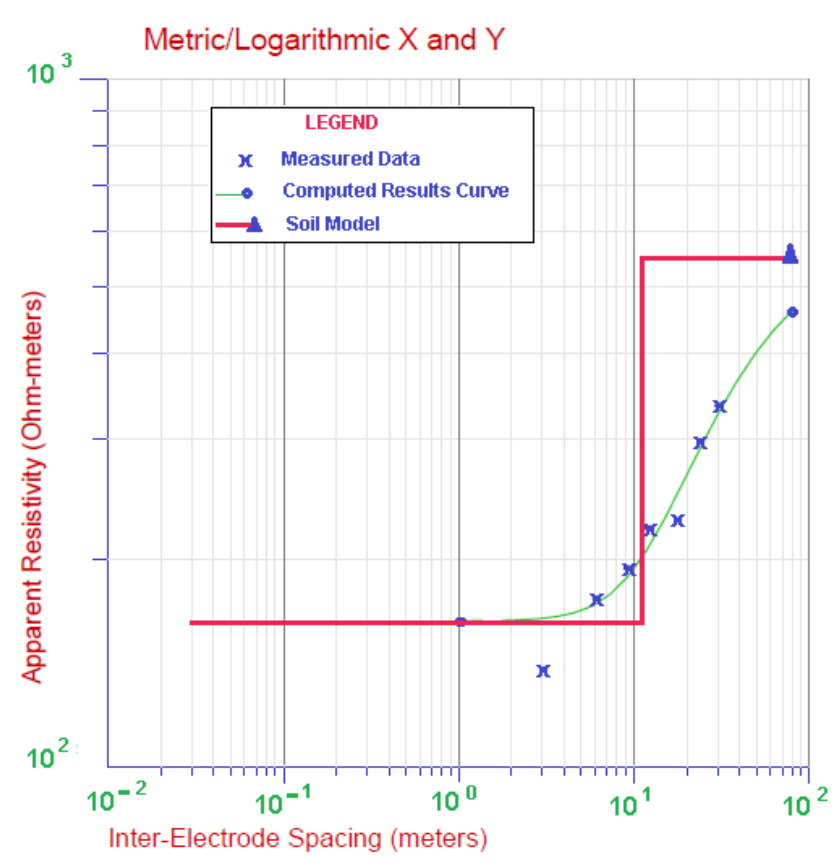

Fig. 1. Soil resistivity plots

\section{B. Step and Touch Voltage Safe Limits (Phase to Ground)}

The second step of the wind farm grounding system analysis is the calculation of the safe step and touch voltage limits. In this study, the guidelines IEC/TS 60479.1 [7] and ENA EG1 [8] were used to calculate safe limits. The method in IEC60479.1 provides a way to calculate a prospective body touch potential and determine the safety of the resulting body current. However, here it is required to determine the safe touch voltage level. Therefore, the method from IEC 60479.1 will be reversed.

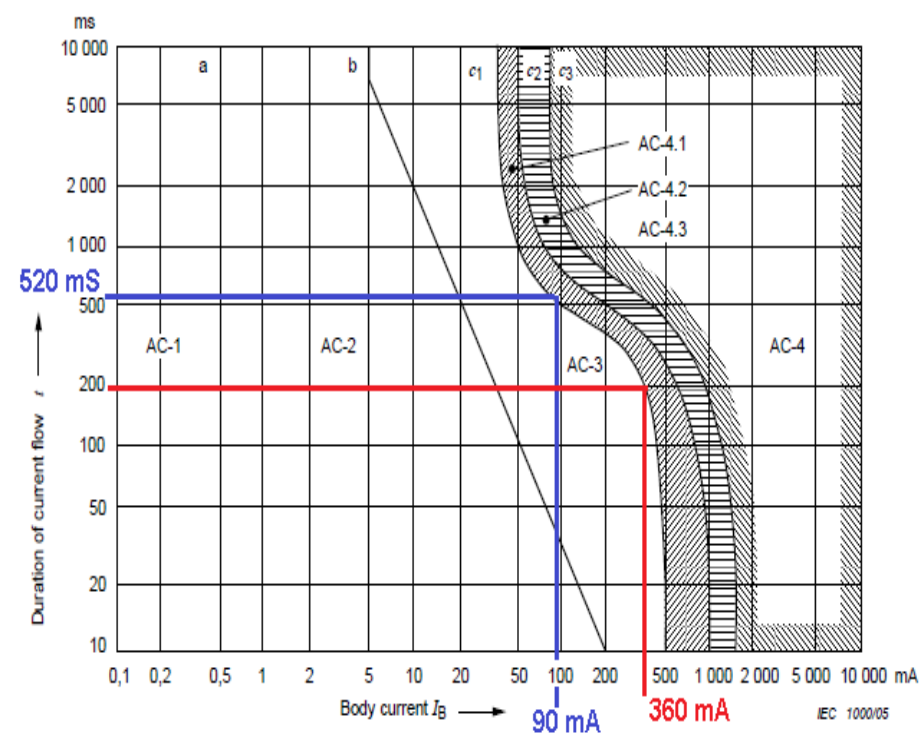

Fig. 2. Allowable a.c. current based on fault clearance time
Referring to Fig. 3, which are the conventional time/current zones of effect of a.c. currents in IEC 60479.1, for all phase to ground faults, compliance must not exceed the AC- 3 region in the figure. Thus, the upper limits of the body current from hand-to-feet for primary protection at $200 \mathrm{~ms}$ and back-up protection at $520 \mathrm{~ms}$ are as shown in Fig. 3.

The body impedances for people are presented in IEC60479.1; however, the body impedance of cattle and horses are not defined yet. In this study the body impedance of cattle with an average weight of $750 \mathrm{~kg}$ has been calculated by multiplying the allowable current limit of a person by a factor of 10 for $50 \mathrm{~Hz}$ fault condition. The maximum allowable step and touch potentials for the grounding system is presented in Table 2. The allowable step and touch potentials are calculated for a $50 \mathrm{~kg}$ person standing outside the primary substation with touch access to metallic fence, metallic infrastructure..

TABLE II. STEP AND TOUCH VOLTAGE SAFE LIMIT

\begin{tabular}{|c|c|c|c|c|c|}
\hline \multirow[b]{2}{*}{$\begin{array}{c}\text { Fault } \\
\text { Clearance } \\
\text { Time }\end{array}$} & \multicolumn{5}{|c|}{ Safe limits } \\
\hline & $\begin{array}{c}\text { Top Layer } \\
\text { Material }\end{array}$ & \begin{tabular}{|c} 
Resistivity \\
{$[\Omega m]$}
\end{tabular} & $\begin{array}{c}\text { Estep50 } \\
{[V]}\end{array}$ & $\begin{array}{c}\text { Etouch50 } \\
{[V]}\end{array}$ & $\begin{array}{l}\text { Estep } \\
\text { Cow } \\
{[k V]}\end{array}$ \\
\hline \multirow{2}{*}{$200 \mathrm{mSec}$} & Natural Soil & 163 & 513 & 233 & 5 \\
\hline & $\begin{array}{l}\text { Wet } \\
\text { Concrete }\end{array}$ & 21 & 292 & 156 & 3 \\
\hline \multirow{2}{*}{$520 \mathrm{mSec}$. } & Natural Soil & 163 & 318 & 181 & 3 \\
\hline & $\begin{array}{l}\text { Wet } \\
\text { Concrete }\end{array}$ & 21 & 181 & 104 & 1.8 \\
\hline
\end{tabular}

Above limits are based on total body impedances of 5\% population. For farm animals different touch and contact scenarios such as $3.5 \mathrm{~m}$ touch and layback contact scenario with large areas of contact can be considered.

\section{PHASE TO GROUND FAULT ASSESSMENT}

It is critical to understand fault scenarios for wind farm grounding system assessment. The wind farm in this case study is located in Australia and accordingly should satisfy National Electricity Rules (NER). Australian NER requires assessing the fault conditions and effect of operation of the maximum generation at transmission and distribution level.

For this case study the fault level of the transmission systems at wind farm point of connection (PCC) has been provided by network operator for system highest voltage. Grid $\mathrm{X} / \mathrm{R}$ ratio and fault level have been used to calculate grid source impedances according to the Thevenin equivalent voltage method for power system analysis. The fault level is almost the same for high summer and high winter generation and load conditions. For this case study the grid worst case scenario can occur at high summer generation.

It is a difficult task to create correct short-circuit model for wind turbine generators and wind farms [10]. Generator modeling requires manufacturer data such as Sub-transient and Transient impedances. Turbine generator reactive characteristics and capacitor compensation provided by manufacture have been used to model case study wind farm with 2 MVA DFIG generators in the Paladin design base 
software. The principal of fault level calculations is based on the guidelines presented in IEC 60909 [9]. Simulation results indicate that worst case ground fault can occur at wind farm main collector bus due to contribution of power network to fault as well as in-service wind turbines (assumed all are inservice with expected maximum generation). Simulation indicates that the fault current of $14800 \mathrm{~A}$ can be present in the $33 \mathrm{kV}$ collector busbar and $9582 \mathrm{~A}$ at wind turbine padmount. PSCAD-EMTDC software has been used for fault transient analysis and Figure 3 shows the fault current transient curve and fault impact to nearby wind turbines LV voltage busbar. It is assumed that fault will be cleared by primary protection within 0.2 second.

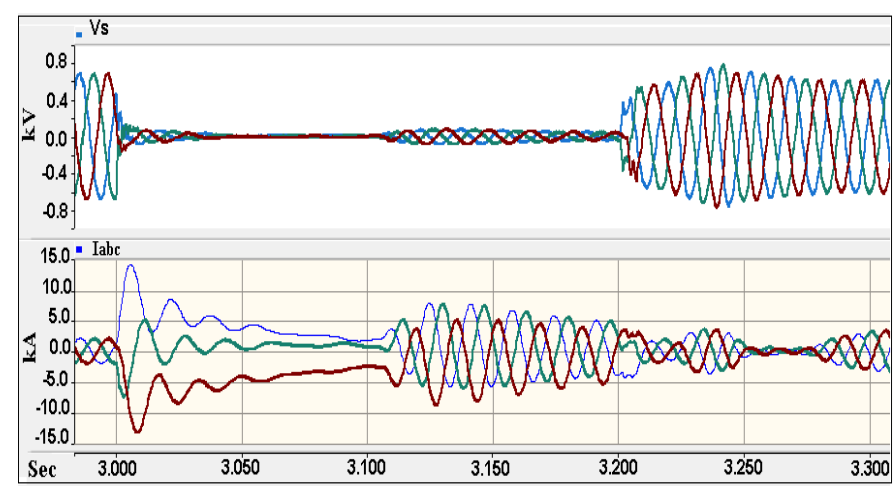

Fig. 3. Fault current transiant with $200 \mathrm{mSec}$ clearance time at padmount

\section{GROUNDING SySTEM SOFTWARE SIMULATION}

The CDEGS software package has been used for the grounding system performance analysis. Wind turbine foundations, tower base padmount substations, $33 \mathrm{kV}$ cable screens between padmounts and primary substation grounding system have been modeled in the HiFREQ computation module of CDEGS software package.

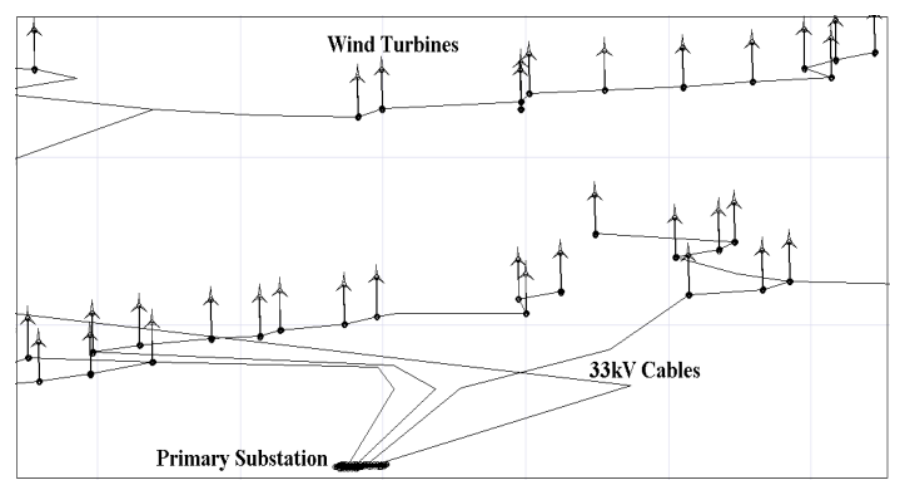

Fig. 4. Wind farm case study model in CDEGS software snpshot

The worst case ground fault scenarios should be considered for grounding analysis to ensure wind farm site is safe to operate. In this case study, wind turbines are connected to main connector via $33 \mathrm{kV}$ cables through Ring Main Unit (RMU) switchgears. All the feeders protected by differential protection and pilot wire as primary protection and overcurrent, ground fault as back-up protection. Accordingly the fault clearance time across the wind farm has the same characteristics therefore; the worst case ground fault will be the highest fault current which has been defined by power system study conducted by Paladin Design Base software.

A power system analysis indicates that the highest ground fault can occur at primary substation where the wind farm is connected to transmission line. Accordingly the phase to ground fault current of $14800 \mathrm{~A}$ has been injected to substation grounding system and the expected soil surface pitential is presented in figures 5 and 6 .

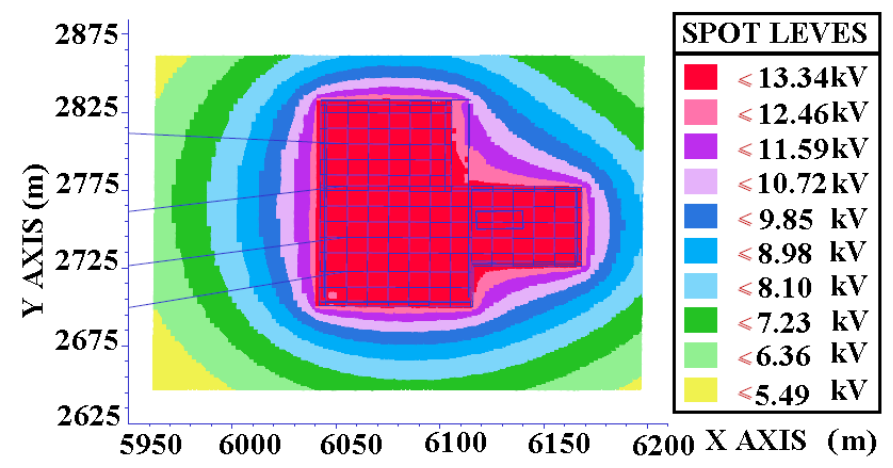

Fig. 5. Primery substation soil surface potential under 14800 A GF

As shown in Figure 5, the ground potential rise of $13.34 \mathrm{kV}$ can be experienced for a fault level of 14800A. The soil voltage profile is shown in Figure 6.

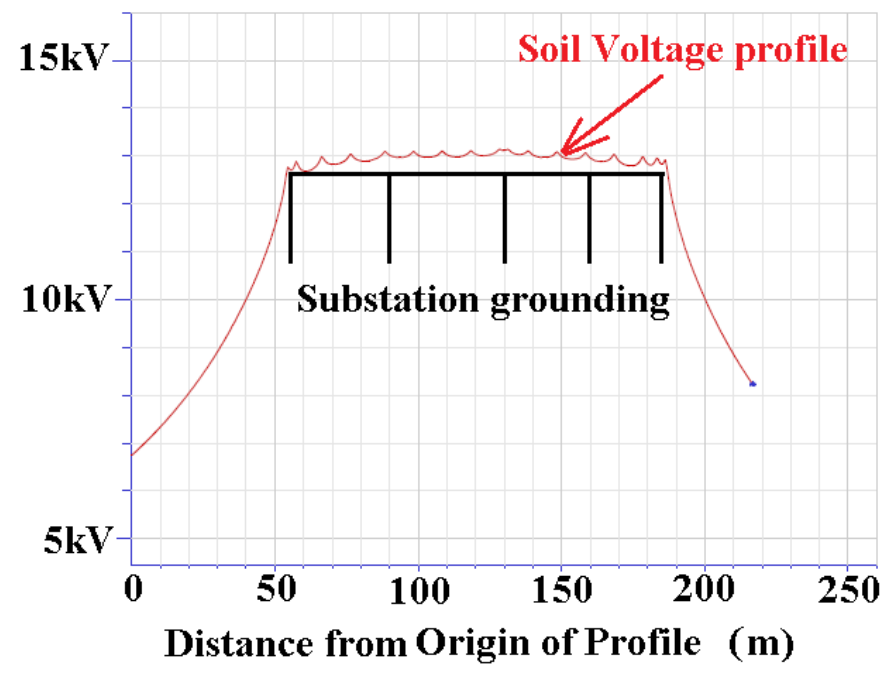

Fig. 6. Soil voltage profile

Figures 5 and 6 indicate that the worst cases touch voltage can occur at the corners of substation boundary fence line. The touch voltage can be calculated by:

Actual touch Voltage $=$ Fence Voltage - Soil voltage 
Similar ground fault analysis has been conducted for worst case wind turbine ground fault in this study. The soil voltage plot is presented in Figure 7 for a fault current of 9582A:

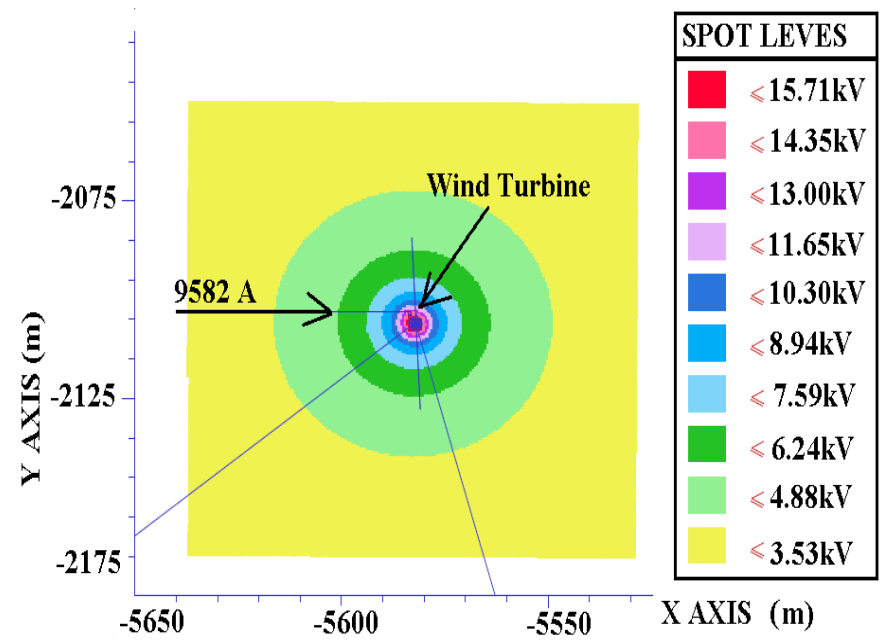

Fig. 7. Wind turbine soil Voltage plot under 9582 A GF

The soil contour voltage around wind turbine under a ground fault of 9582A is shown in Figure 8- 3D plot.

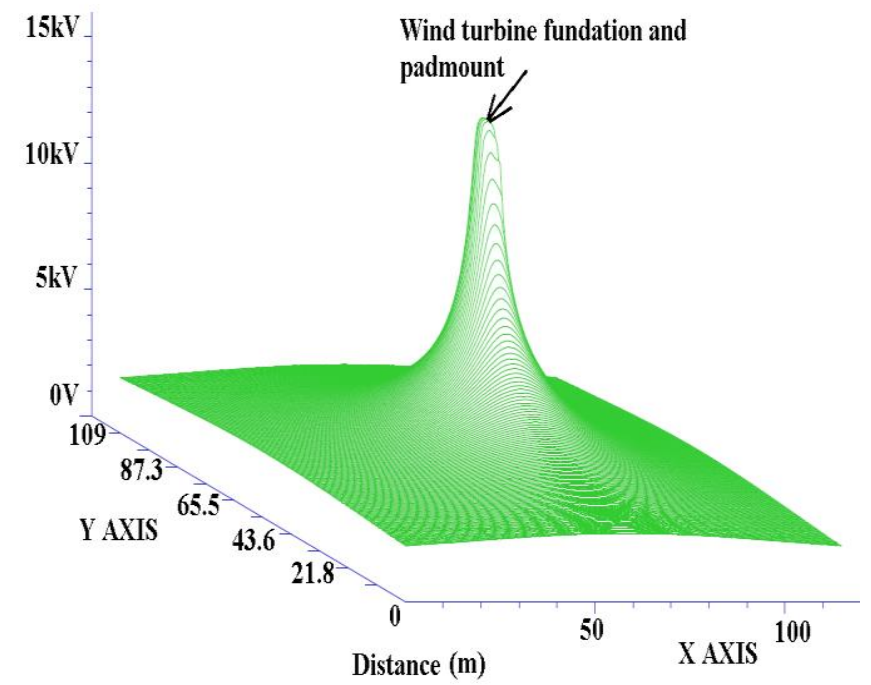

Fig. 8. Wind turbine $3 \mathrm{D}$ soil voltage profile

The fault levels at wind turbines are lower than primary substation but since they have a smaller foot print and higher grounding system impedance, the GPR will be higher than primary substation.

Step and touch voltages for people are calculated based on $1 \mathrm{~m}$ contact distance and farm animal contact is based on $3.5 \mathrm{~m}$ contact distance as shown in Figure 9. The turbine metallic structure such as hand rail or tower body can have a GPR of $15.71 \mathrm{kV}$ with respect to remote ground. The soil surface potential approximately $1 \mathrm{~m}$ away from turbine is $13.19 \mathrm{kV}$.
Therefore actual touch voltage around turbine base is $2520 \mathrm{~V}$ which is well above the allowable safe limit. Farm animals with $3.5 \mathrm{~m}$ contact are subjected to contact voltage of $6.38 \mathrm{kV}$ which is also above the safe limit.

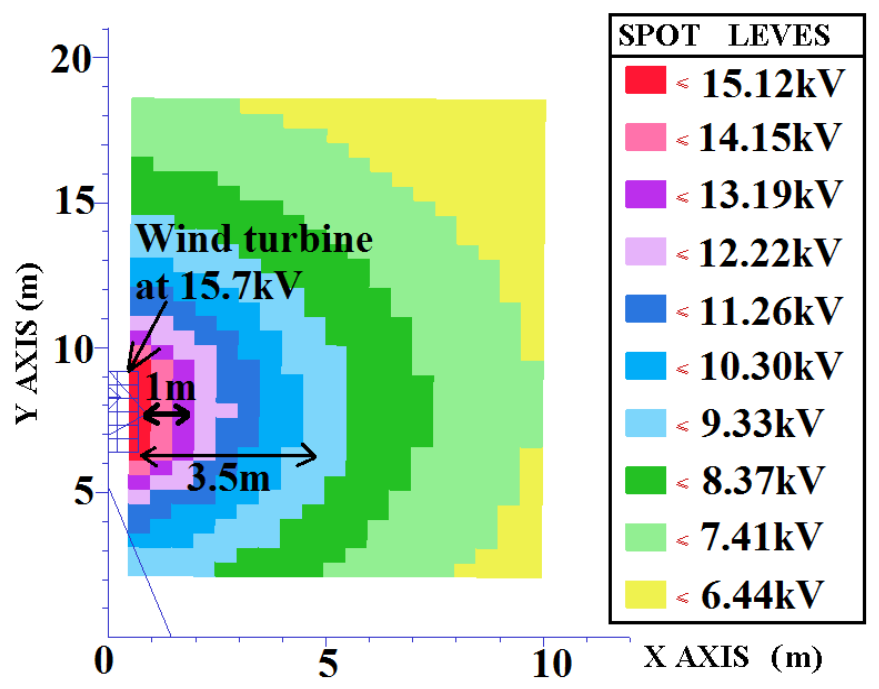

Fig. 9. Soil voltage profile and voltage gradiants

The following methods are recommended to limit phase to ground fault level and accordingly lower the GPR:

- Neutral Ground Resistor.

- Lower the impedance of wind turbine grounding system.

- Improve the fault current return path.

- High resistance layer (such as gravel) around the wind turbine

Neutral ground resistor method was not feasible for this project due to power system requirement. It is not an easy task to lower wind turbines grounding system as normally turbines are located at elevated ground level or at the top of hills therefore they have high resistance ground underneath. Hence lowering the grounding system resistance of wind turbine might not be feasible.

Another method for improving the ground fault condition is to provide better fault return path for fault current. This is a feasible method and normally can be achieved by following two solutions:

- Increasing the cross section of power cables screen's between wind turbines padmounts. The screen of power cables has some construction restrictions which should be considered. Normally the screens of power cables are limited to $70 \mathrm{~mm}^{2}$ and $90 \mathrm{~mm}^{2}$. Higher size of screens can be considered after cost analysis.

- Installation of bare wire next to the power cable. Normally wind turbines consist of a distribution network to collect generated power by each turbine. The distribution system can be $11 \mathrm{kV}, 22 \mathrm{kV}$ or $33 \mathrm{kV}$ in Australia with direct buried cable arrangement. To 
improve the earthing system it is recommended to lay a $70 \mathrm{~mm}^{2}$ bare conductor next to the power cable. This conductor provide another parallel path to phase to ground fault current, also it will dissipate the return current as shown in below Figure 10.

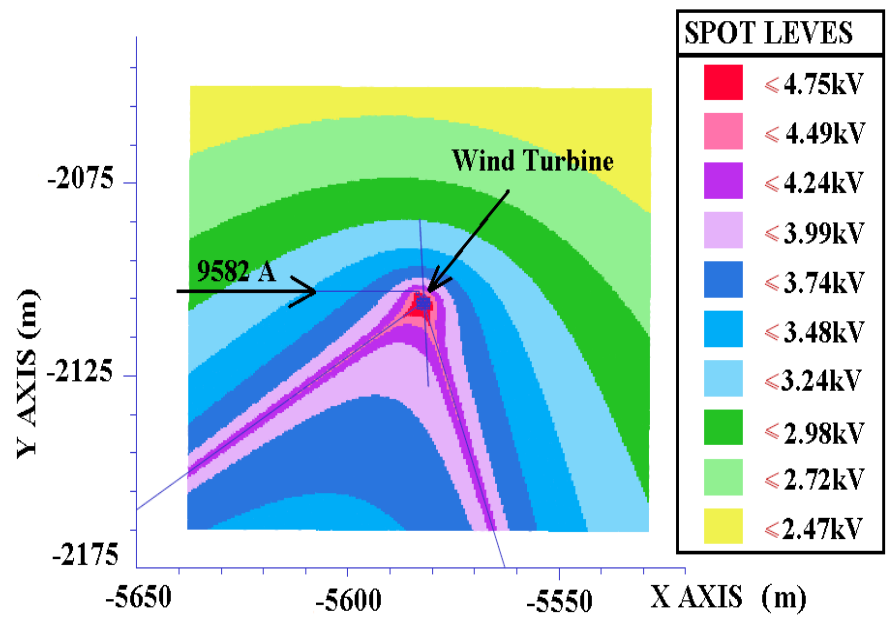

Fig. 10. Wind turbine soil Voltage plot under 9582 A GF with bare wire

As shown in Figure 10, wind turbine soil potentials and GPR can be reduced significantly by using additional bare grounding conductor.

- Installation of high resistance layer around turbine base is another mitigation method which can increase the safe touch voltage limit. Figure 11 bellow shows an example of this mitigation method.

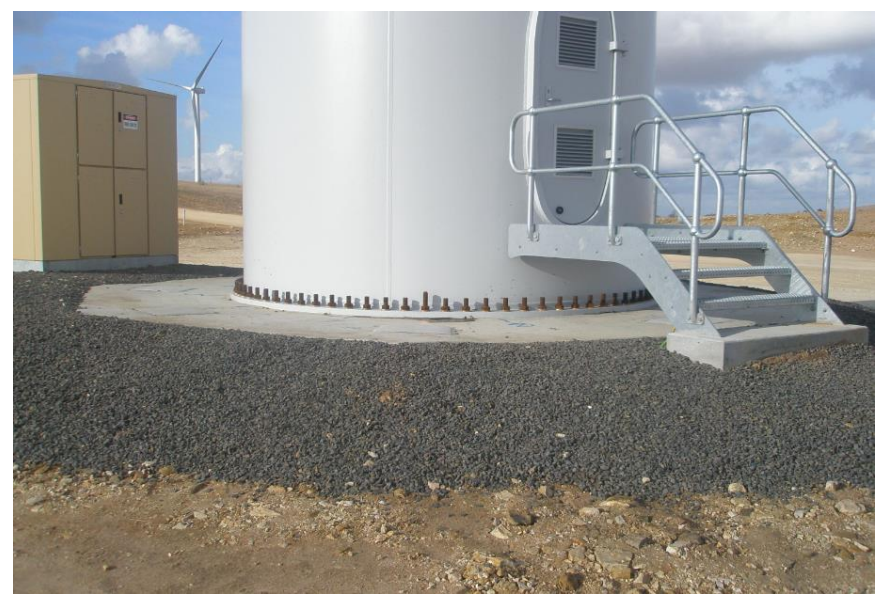

Fig. 11. An example of gravel installation around turbine tower base

\section{WIND TURBINES LIGHTNING ASSESSMENT}

The lightning stroke risk is a common issue for wind farms since the factor of height and standalone conditions can provide good cloud-to-ground discharge path. Wind turbines blades are more likely to be stroked by lightning as they are higher than other nearby infrastructures. So it is essential to minimize the impact of lightning on the turbines and their blades.
Normally several surge protection devices are used in wind turbine hub, nacelle, tower and padmounts which will define lightning protection zones. The earthing system performance is critical in surge protection device operation. Since the lightning wave contains high frequency waveforms, the cable screens and grounding connections between wind turbines won't play major role in lightning energy dissipation. Therefore it is recommended to maintain wind turbine standalone grounding resistance lower than $10 \Omega$.

To access the lightning strike impact on wind turbine grounding system, a lightning strike current waveform with the maximum $30 \mathrm{kA}$ peak as recommended in Table 1 of IEC 61400-24 [11] has been modeled in the FFTSES, FFT and HIFREQ computation modules of CDEGS software package. The lightning strike wave which applied to the turbine grounding system is presented in Figure 12.

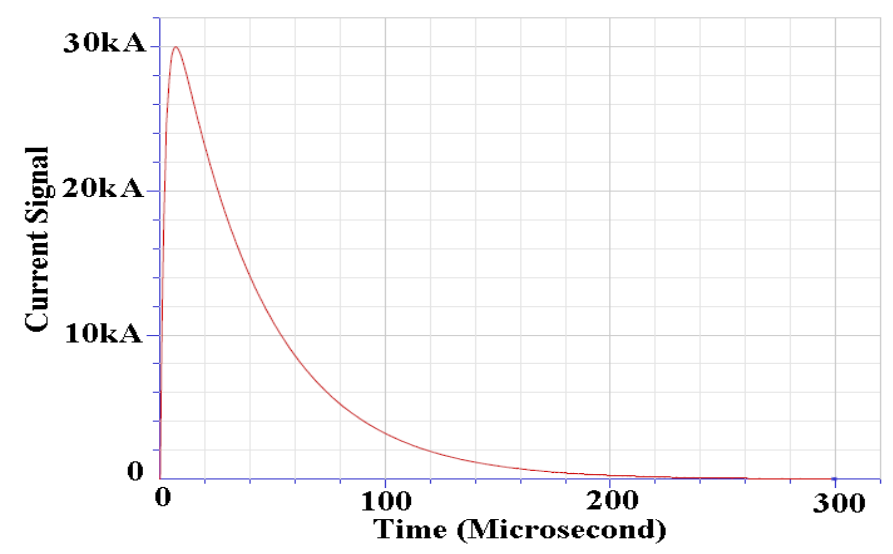

Fig. 12. Lightning strike waveform

The lightning current wave was modelled in the FFTSES module which has generated an initial 17 frequencies up to $0.85 \mathrm{MHz}$. Since there are resonance effects in the initial simulation results and turbine grounding system response, several additional frequencies have been added in the forward Fourier transform simulation. The following frequencies were recommended by software computation as additional frequencies:

TABLE III. LIGHTNING CURRENT WAVEFORM FREQUENCIES

\begin{tabular}{|c|c|c|c|c|c|}
\hline $\begin{array}{c}\text { Simulation } \\
\text { Stage }\end{array}$ & \multicolumn{5}{|c|}{ Frequency [Hz] } \\
\hline \multirow{2}{*}{$\begin{array}{c}\text { Pre- } \\
\text { computed } \\
\text { Simulation }\end{array}$} & 00000 & 3333 & 6666 & 10000 & 13333 \\
\cline { 2 - 6 } & 240000 & 360000 & 480000 & 600000 & 720000 \\
\cline { 2 - 6 } & 840000 & 853333 & -- & -- & -- \\
\hline $\begin{array}{c}\text { After } \\
\text { initial } \\
\text { simulation } \\
\text {. }\end{array}$ & 53333 & 63333 & 83333 & 163333 & -- \\
\hline $\begin{array}{c}\text { Second } \\
\text { simulation }\end{array}$ & 76666 & 90000 & 100000 & 136667 & -- \\
\hline
\end{tabular}


The wind turbine grounding system time domain response to the lightning strike with above frequencies has been simulated using inverse Fourier transform in Figure 13. Figure 14 shows the magnitude of the frequency spectrum response. Obviously, additional frequencies could have been added to refine the plots but it is clear that with this limited number of frequencies, the essential part of the response has been captured already. Simulation results indicate that highest voltages due to lightning can occur at $480 \mathrm{kHz}, 720 \mathrm{kHz}$ and $840 \mathrm{kHz}$.

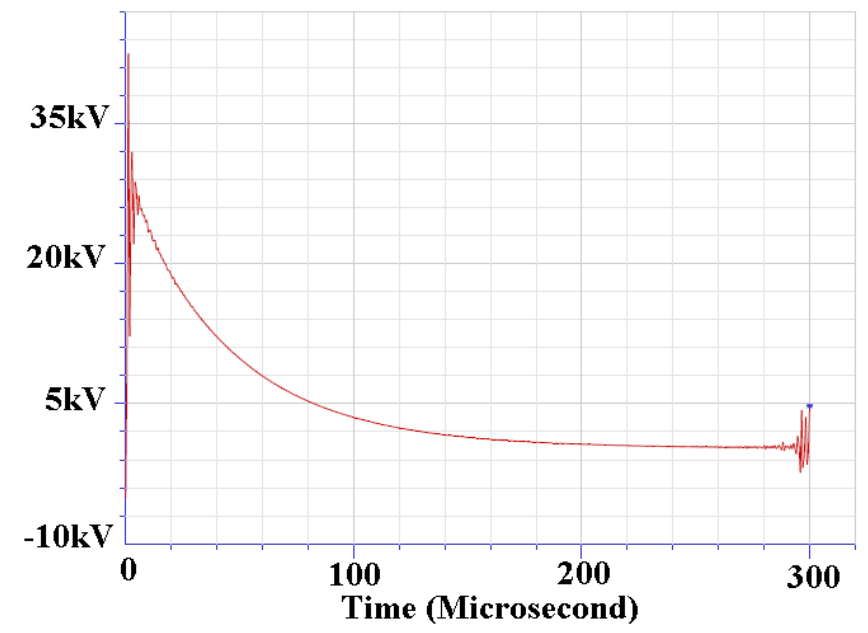

Fig. 13. Wind turbine time domain response to the lightning strike

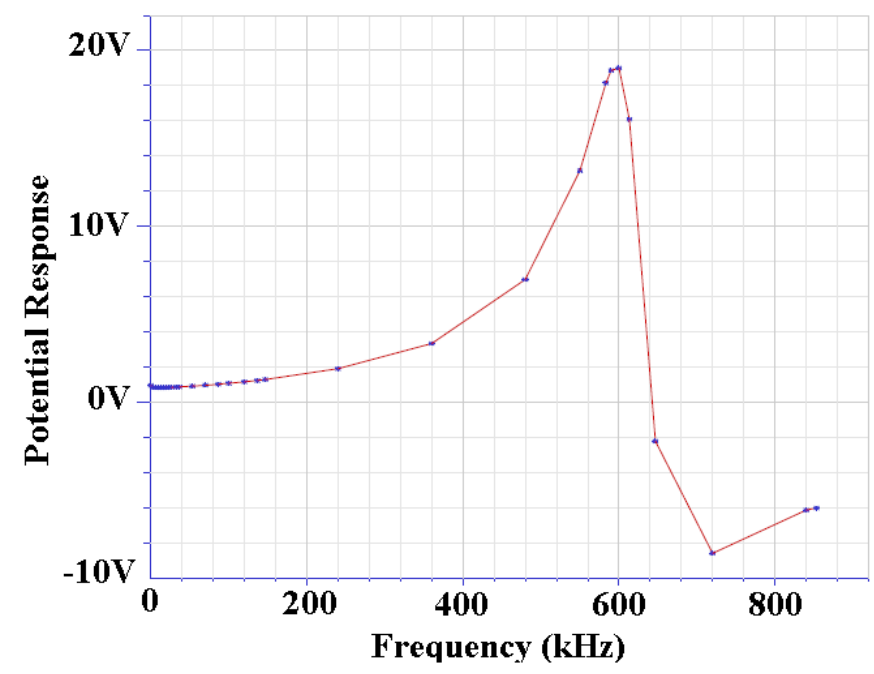

Fig. 14. Wind turbine unity response spectrum to current wave frequencies

It is possible to use the simulation results for surge protection device selection. It is also possible to use the above results for power system insulation coordination and basic lightning impulse insulation level (BIL) study.

\section{CONCLUSION AND RECOMMENDATIONS}

It is critical to understand and simulate realistically fault scenarios for wind farm grounding system assessment. The grounding system analysis requires accurate soil resistivity measurement. It is recommended to conduct individual soil resistivity tests at the proposed locations of each wind turbine.

All the phase to ground fault scenarios should be considered and simulated via appropriate power system and grounding system analysis software. It is recommended to consider contribution from the service provider grid and the wind farm contribution to the fault simultaneously.

Phase to ground fault currents impact on cable screens should be included in the study to accurately define the ground potential rise and fault current split. It is recommended to install bare grounding conductors in parallel with power cables. Provision for future maintenance and impact of soil acidity should be considered during the design development. It is a good practice to provide a layer of gravel around wind turbines and substation to increase touch and step voltage safety limits. To mitigate and avoid damage to the equipment it is recommended to conduct a lightning assessment at critical wind turbine locations.

\section{REFERENCES}

[1] IEEE Std 81-2012, IEEE Guide for Measuring Earth Resistivity, Ground Impedance, and Earth Surface Potentials of a Grounding System, 28 Dec. 2012.

[2] IEEE Std 80-2000, IEEE Guide for Safety in AC Substation Grounding, (revised to 80-2013), 15 May 2015.

[3] Technical Report, IEC 61400-24, 2002, Wind turbine generator systems, Part 24: Lightning protection, version 01-06-2010.

[4] AS/NZS 1768:2007, Lightning protection, Australian/New Zealand Standard.

[5] T. S. Sorensen, J. A. Plumer, J. Montanyà, T. H. Krogh, B. Hermoso, T. Birk1, Gehlhaar, B. McNiff, K. Bertelsen and V. Peesapati, "The update of IEC 61400-24 Lightning protection of wind turbine," 29th International Conference on lightning protection, Uppsala, Sweden, 2008 .

[6] J. Liu and F. P. Dawalibi "Wind Turbine Farm Network Grounding Design Using Integrated Simulation Methods and Techniques", International Conference on Future Power and Energy Engineering (ICFPEE), June 2010.

[7] Technical Report, IEC 60479-1:2007, Effects of current on human beings and livestock - Part 1: General aspects, publication date 13-072005 .

[8] ENA EG1-2006, Substation Earthing Guide, Energy Networks Association, Pub: Standards Australia, Dec 2006.

[9] Technical Report, IEC 60909-1: 2002, Short-circuit currents in threephase a.c. systems-Part: 1 Factors for the calculation of shortcircuitcurrents according to IEC 60909-0, 2nd edition, 2002-07.

[10] Joseph R. Williams, Benjamin Karlson, "Wind Power Plant ShortCircuit Modeling”, August 2012.

[11] TR 61400-24, Wind turbine generator systems - Part 24: Lightning protection, First edition, July 2002. 